\title{
Entes territoriales de escala comarcal en la Administración local española
}

\author{
Joan Carles Membrado-Tena \\ Universitat de València. Departament de Geografia \\ joan.membrado@uv.es
}

Recepción: marzo de 2015

Aceptación: julio de 2015

\section{Resumen}

El mapa autonómico español creado a partir de 1978 se superpuso al esquema territorial que ya existía, formado por provincias y municipios, y así ha tenido que convivir con un mapa anterior obsoleto e ineficiente. La mayoría de los municipios son demasiado pequeños para proveerse de servicios, y esta insuficiencia en la prestación de los mismos no ayuda a frenar el despoblamiento rural. En algunas comunidades autónomas, se han intentado crear entes intermedios entre la provincia y el municipio — generalmente, comarcaspara tratar de corregir los desequilibrios territoriales. Solo algunas de estas comunidades han llevado finalmente a cabo un proceso de transferencia de competencias a estos nuevos entes intermedios, pero muchas veces dichas competencias topan con las que ya poseen las diputaciones, entidades que, por otra parte, lejos de perder peso, están siendo reforzadas por el actual Gobierno de España.

Palabras clave: comarca; área funcional; área metropolitana.

\section{Resum. Ens territorials d'escala comarcal en l'Administració local espanyola}

El mapa autonòmic espanyol creat a partir de 1978 es va superposar a l'esquema territorial que ja existia, format per províncies i municipis, i així ha hagut de conviure amb un mapa anterior obsolet i ineficient. La majoria dels municipis són massa petits per proveir-se de serveis, i aquesta insuficiència no ajuda a frenar el despoblament rural. En algunes comunitats autònomes, s'ha intentat crear-hi ens intermedis entre la província i el municipi - generalment, comarques - per intentar corregir els desequilibris territorials. Les competències transferides a aquests nous ens intermedis topen sovint amb les que ja posseeixen les diputacions, entitats que, d'altra banda, lluny de perdre pes, estan sent reforçades per l'actual Govern d'Espanya.

Paraules clau: comarca; àrea funcional; àrea metropolitana. 
Résumé. Organes Territoriaux au niveau de la "comarca" dans l'administration locale espagnole

La nouvelle carte espagnole des communautés autonomes (c.-à-d. la carte régionale), créée à partir de 1978, a été superposée au schéma territorial qui existait auparavant, constitué de provinces et de municipalités, et elle a donc dû coexister avec une carte plus ancienne, obsolète et inefficace. La plupart des municipalités sont trop petites pour fournir les services nécessaires, ce qui ne contribue pas à freiner l'exode rural. Dans certaines communautés autonomes on a créé des organes intermédiaires entre la province et la municipalité — généralement des comarcas - pour tenter de corriger les déséquilibres régionaux. Les compétences transférées à ces nouveaux organes intermédiaires se heurtent souvent à celles qui sont déjà sous la responsabilité des diputaciones (c.-à-d. les conseils provinciaux), et qui, loin de perdre du pouvoir, ont été renforcées par le gouvernement actuel de l'Espagne.

Mots-clés: comarca; région fonctionnel; région métropolitaine.

\section{Abstract. District-level Territorial Bodies in Spain's Local Government}

The map of Spanish regions, known as autonomous communities, created in 1978 and the following years was superimposed on the previously existing territorial scheme consisting of provinces and municipalities, and has since been forced to coexist with an older, obsolete and inefficient map. Most municipalities are too small to afford the services that they need, which does not help to curb rural depopulation. In some autonomous communities, new, intermediate governing bodies between provinces and municipalities - typically counties (comarcas) - have been created to correct regional imbalances. The powers transferred to these new intermediate governments often conflict with those being held by the provinciallevel governments (diputaciones) which, far from losing power, have been reinforced by the current government of Spain.

Keywords: comarca; functional area; metropolitan area.

\section{Sumario}

1. Introducción 4. Conclusiones

2. Metodología Referencias bibliográficas

3. Resultados y discusión

\section{Introducción}

La actual división oficial en dos niveles, la provincia y el municipio, ha logrado penetrar de manera profunda en la conciencia de la sociedad española. No obstante, ciertos sectores han denunciado sus inconvenientes y han propuesto alternativas para subsanarlos. Por un lado, señalan que los municipios más pequeños - que son la gran mayoría - muestran, en muchos casos, signos de inadecuación a la realidad presente: deben prestar servicios a sus munícipes, pero la grave despoblación que sufren desde hace décadas los ha dejado con tan pocos recursos que difícilmente pueden hacerlo. Por otra parte, hasta el 
momento, las provincias se han mostrado poco eficaces por lo que respecta a la ordenación racional del territorio: el centripetismo que ejercen las capitales tiene como resultado que cada vez una mayor proporción de la población provincial acabe residiendo en sus áreas urbanas, lo que acentúa la desigualdad demográfica y económica sobre el territorio.

En algunas comunidades autónomas periféricas, se han implementado entes intermedios entre la provincia y el municipio: comarcas, áreas funcionales, áreas metropolitanas, etc. En el caso concreto de Cataluña, se pretendía crear un ente intermedio entre la comunidad y el municipio como sustituto de la provincia: la veguería. Estos entes locales intermedios poseen funciones muy diversas según la comunidad (descentralización administrativa, planificación territorial, desarrollo endógeno, etc.), y sus competencias suelen entrar en concurrencia con las de las diputaciones provinciales.

En este artículo, vamos a describir, a modo de preámbulo, los inconvenientes que, por su compartimentación y heterogeneidad, supone el actual mapa municipal español, y también el cuestionamiento de las diputaciones provinciales por parte de las formaciones políticas actualmente en la oposición española, que plantean su eliminación por ineficaces y caciquiles, a pesar de que el Gobierno las ha reforzado recientemente con la aprobación de la Ley 27/2013, que invade competencias municipales y fiscaliza a los ayuntamientos. La irracionalidad del mapa municipal y el cuestionamiento de las diputaciones han llevado a algunas comunidades a intentar solventar los desequilibrios territoriales mediante la creación de entes intermedios, normalmente de escala comarcal. El primer objetivo de este artículo, que veremos en el apartado de resultados, será analizar en qué comunidades autónomas se ha llevado a cabo un proceso de comarcalización y en qué grado se ha ejecutado dicho proceso (de manera meramente simbólica, a efectos estadísticos, a título orientativo para la planificación territorial o con determinadas competencias transferidas). El segundo objetivo, que veremos en la discusión de resultados y sintetizaremos en la conclusión, es averiguar si en aquellos territorios donde se han implementado las comarcas u otros entes territoriales intermedios, estos han cumplido el objetivo para el que fueron creados.

\section{Metodología}

En este artículo, partimos de una realidad territorial consistente, por un lado, en municipios y provincias, heredados del estado liberal de la España de la primera mitad del siglo xIX, y, por otro, en comunidades autónomas, fruto de la Constitución de 1978. Analizamos los casos de las comunidades autónomas periféricas (salvo las uniprovinciales y Canarias, donde ya no existen las diputaciones), en las que se ha llevado a cabo — en mayor o menor grado- una reforma de esta organización territorial en tres niveles, mediante la creación de comarcas u otro tipo de entes intermedios entre la provincia y el municipio. A lo largo del artículo, veremos cuáles han sido los resultados de dicha implementación en cada una de las comunidades analizadas y discutiremos dichos 
resultados (punto 3), mientras que, en la conclusión (punto 4), reflexionaremos sobre si las comarcas u otros entes han desempeñado correctamente el cometido para el que fueron creados (corrección de desequilibrios territoriales, descentralización administrativa, planificación territorial, etc.).

Para ilustrar los principales proyectos de comarcalización de los territorios analizados (Andalucía, Valencia, País Vasco, Galicia, El Bierzo — dentro de la Comunidad Autónoma de Castilla y León-, Aragón y Cataluña), se ha elaborado una serie de mapas a partir del programa ArcGIS de ESRI, confeccionados mediante los datos ofrecidos por cada uno de los organismos oficiales (normalmente, gobiernos autonómicos) impulsores de dichos proyectos. El sistema de coordenadas usado para la confección de los mapas ha sido el ETRS (European Terrestrial Reference System) 1989 UTM (Universal Transversal Mercator), obligatorio en España desde el 1 de enero de 2015. Para Cataluña (figura 7), hemos utilizado el huso 31 norte; para Galicia (figura 5), el 29 norte, y para el resto de mapas, el huso 30 norte. Para la confección de los mapas, hemos partido de dos capas vectoriales o shapes principales: la de comarcas y/o áreas funcionales, y la de provincias, aunque también hemos usado la de municipios (en Galicia y El Bierzo) y la de veguerías (en Cataluña).

\section{Resultados y discusión}

\subsection{Antecedentes: municipios y provincias}

El mapa de municipios de España se caracteriza tanto por el elevado número de estos (más de 8.000) como por su gran heterogeneidad en cuanto a tamaño geográfico y población. Este mapa municipal se basa, jurídica y territorialmente, en la instauración del estado liberal en la España de la primera mitad del siglo XIX (Burgueño y Lasso, 2002). A lo largo de diversas reformas llevadas a cabo durante el siglo XIX y durante los años 1960-1970, se redujo significativamente el número de municipios: solo entre 1842 y 1857 desaparecieron casi 2.000 ayuntamientos (Orduña, 2003). A pesar de ello, el mapa municipal actual sigue siendo, en gran parte de España, una rémora del pasado: de un tiempo en que la gente aún se desplazaba a pie (Nadal, 1987). Ante este mapa tan obsoleto, sería racional llevar a cabo una reforma de los límites municipales actuales, no solo para fusionarlos y, con ello, aumentar su tamaño y su viabilidad económica, sino también para resolver el problema de las discontinuidades territoriales municipales: los 85 territorios compartidos por diversos ayuntamientos (llamados parzonerías en el País Vasco y Navarra) y los 700 enclaves (Burgueño y Guerrero, 2014: 28; Torres, 1998; Gil Olcina, 1999). Las comunidades autónomas podrían haber iniciado un proceso de agregación de municipios con el fin de diseñar ámbitos territoriales más racionales. Sin embargo, cuando, desde alguna administración, se ha intentado llevar a cabo una reforma para concentrar municipios, normalmente la reacción contraria a dicha fusión ha sido virulenta.

Muchos países europeos, caracterizados hasta mediados del siglo xx por una desagregación municipal similar o superior a la española, iniciaron procesos 
radicales de fusión de municipios entre 1950 y 1992 (Rodríguez, 2006: 117) ${ }^{1}$. Aunque la mayoría de gobernantes españoles, de cualquier signo, acepta que la dispersión del mapa municipal es un grave problema, en realidad nadie se atreve a llevar a cabo una reforma en este sentido, por el precio político que ello le podría suponer (Burgueño, 2001: 202) ${ }^{2}$.

El Gobierno español, en lugar de atajar el verdadero problema que representan los más de 8.000 ayuntamientos, ha optado por reforzar el papel de las diputaciones provinciales para suplir las carencias de los pequeños municipios mediante la Ley 27/2013, de 27 de diciembre, de racionalización y sostenibilidad de la Administración local (LRSAL), aprobada por el Partido Popular. Esta ley propone que la prestación de determinados servicios mínimos en los municipios menores de 20.000 habitantes se haga mediante la coordinación por parte de las diputaciones, con lo cual los municipios afectados - que son la inmensa mayoría- solo podrán gestionar en este ámbito lo que la diputación correspondiente les permita. Mendizàbal (2014: 25-26) considera esta reforma centralizadora y favorecedora de la iniciativa privada, que podría pasar a desempeñar ciertas funciones que hoy llevan a cabo los municipios, en especial en ámbitos relacionados con el estado del bienestar. Ferret (2014: 38) piensa que esta ley se inserta en un proceso centralizador, ya que supone un retroceso al siglo XIX, cuando las diputaciones - y en última instancia el Estado- tenían cierta capacidad intervencionista sobre los municipios. Este mismo autor (2014: 39-40) cree que dicha ley supone un cambio radical en la visión sobre la capacidad gestora de aquellos (especialmente los de menos de 20.000 habitantes), puesto que antes podían llevar a cabo cualquier acción que favoreciese a la comunidad vecinal, pero ahora solo podrán hacer aquello que la ley les reserve o lo que se les delegue, siempre que tengan sus cuentas saneadas. Todo este cambio viene condicionado, en última instancia, por la reforma del artículo 135 de la Constitución, que prioriza el pago de la deuda frente al gasto social. Y los municipios no son los únicos perjudicados por la LRSAL: el carácter fiscalizador de la misma también afecta a otros entes locales, como las mancomunidades y los consorcios municipales, que corren el riesgo de ser disueltos si no mantienen también sus cuentas bien saneadas. Aunque la LRSAL se inspira en unos principios de centralización, desconfianza hacia el mundo local y prioridad absoluta del saneamiento de las cuentas frente a la

1. Alemania redujo su número de 24.272 a 8.077 (-67\%); Reino Unido, de 2.028 a 484 (-76\%); Bélgica, de 2.669 a 589 (-78\%), y también lo redujeron Dinamarca (-80\%), Suecia $(-87 \%)$ o Bulgaria (-88\%). En 2010, y con la crisis económica como justificación, también Grecia redujo el número de sus municipios, de 2.359 a 596 (Mendizàbal, 2014: 28).

2. En Cataluña, hubo una propuesta de reforma municipal en 1981, que no se llegó a llevar a cabo. En dicha propuesta, de Lluís Casassas y Joaquim Clusa, se hablaba de un centenar de municipalías, unidades territoriales que hubieran tenido todas las competencias de la Administración local (no hubiera habido ni municipios ni comarcas) formadas por varios núcleos de población y cuya delimitación se basaba, por un lado, en las relaciones humanas cotidianas y, por otro, en criterios cuantitativos tales como que hubiera una distancia inferior a 6 kilómetros entre núcleos compactos y un mínimo de 10.000 habitantes siempre que fuera posible (Mendizàbal, 2014: 29-30). 
prestación de servicios públicos, Burgueño (2014: 100-101) también encuentra algún aspecto positivo en ella, como el impulso — con medidas concretas relacionadas con una mayor financiación- para incentivar las fusiones municipales.

La aprobación de la LRSAL en 2013 refuerza el peso de las diputaciones, ya que, por un lado, les otorga un papel más determinante en la coordinación de determinados servicios mínimos y, por otro, les transfiere nuevas competencias (recaudación tributaria, administración electrónica y contratación centralizada). Este renovado protagonismo de la diputación provincial contrasta con el aumento, en los últimos tiempos, de las voces críticas hacia dicha institución, entre las cuales hay partidos políticos ${ }^{3} \mathrm{y}$ asociaciones de empresarios, que consideran que cuatro niveles de administración son excesivos. Solamente el Partido Popular defiende sin ambages la vigencia de las diputaciones. En general, estas voces críticas con las diputaciones ven en ellas organismos obsoletos e ineficaces, e incluso algunas las acusan de favorecer el clientelismo, el caciquismo y la corrupción. Sugieren que los servicios que las diputaciones prestan a los pequeños ayuntamientos se transfieran a los gobiernos autonómicos respectivos (como ya sucede en las comunidades uniprovinciales), lo que supondría un ahorro de cientos de cargos políticos en toda España.

A pesar de las críticas que recibe la institución provincial, el inmovilismo en cuanto a la supresión de las diputaciones ha sido total por parte de cualquiera de los partidos gobernantes en España desde la recuperación de la democracia hasta ahora.

\subsection{Comarcas y otros entes intermedios entre municipios y provincias}

La LRSAL, que, como hemos dicho, refuerza el papel de las diputaciones, contempla además que las nuevas atribuciones de cooperación y asistencia a municipios pequeños y medianos puedan ser ejercidas no exclusivamente por aquellas, sino también por los diversos entes locales intermedios que existan en aquellas comunidades con una organización territorial propia (Argullol, 2014: 50).

A pesar de que muchos estatutos de autonomía contienen artículos donde se abre la posibilidad de reorganizar la comunidad a partir de unidades territoriales intermedias — normalmente, comarcas - entre el municipio y la provincia que puedan ayudar a corregir los desequilibrios demográficos, la mayoría de gobiernos autonómicos ha optado por el inmovilismo y ha dado por buena la organización territorial basada en el municipio y la provincia. Los territorios donde sí que se han llevado a cabo procesos de reorganización y autodefinición territorial — donde la comarca tiene diversas competencias transferidas— son

3. Entre las fuerzas políticas partidarias de la supresión de las diputaciones provinciales, se encuentran IU, Iniciativa, UPyD, ERC, BNG, Compromís, CiU y Ciudadanos. En el caso del PSOE, Rubalcaba propuso la eliminación de las diputaciones provinciales en 2011, sin que dicha propuesta se recogiese en su programa electoral para las elecciones generales de 2011 (Bernadí y Galán, 2012: 11). 
las comunidades autónomas de Cataluña y Aragón, el territorio histórico o provincia de Álava y la comarca castellano-leonesa de El Bierzo.

En otras zonas periféricas españolas, hubo algún intento poco exitoso de comarcalización, como en Andalucía y Galicia, mientras que en Valencia, donde las comarcas no son oficiales, hay 15 macrocomarcas que funcionan como áreas funcionales de descentralización de los servicios de la Generalitat. El mismo número de áreas funcionales — no oficiales, pero sí referenciales para el desarrollo integral del territorio- posee el País Vasco, que, a su vez, cuenta con comarcas oficiales - con competencias transferidas desde la Diputación Foral- en el territorio de Álava, que no coinciden con las áreas funcionales.

Por lo que respecta a Navarra, desde la edad media y hasta la creación de la autonomía, el territorio se dividió en merindades (Pamplona/Iruña, Tudela, Estella/Lizarra, Olite/Erriberri, Sangüesa/Zangoza), que hoy en día carecen de competencias administrativas, aunque sus territorios coinciden con los vigentes partidos judiciales. En la actualidad, se suele dividir Navarra en tres comarcas de tipo geográfico: la Ribera, cuyos núcleos más destacados son Tudela y Corella; la zona media, donde destacan Estella/Lizarra y Sangüesa/ Zangoza, y la montaña, donde están Pamplona/Iruña y los valles prepirenaicos y pirenaicos. En cuanto a Asturias, su estatuto de autonomía contempla la posibilidad de ordenación en comarcas, que no se han desarrollado legalmente hasta ahora. En la actualidad, solo existen dos comarcas — las de Avilés y del Nalón- que funcionan como mancomunidades para la prestación de los servicios a los municipios y para la ordenación, planificación y promoción exterior de las mismas. Desde el punto de vista de circunscripciones electorales para elecciones autonómicas, existen tres comarcas: Asturias Oriental, Central y Occidental (figura 1).

Por lo que respecta a Cantabria y a La Rioja, sus estatutos respectivos reconocen la comarca como entidad local, pero hasta ahora no la han desarrollado. Por lo general, La Rioja suele dividirse fisiográficamente en Alta, Media y Baja, cada una de ellas con una zona de montaña (Sistema Ibérico) y una de valle (depresión del Ebro). En Cantabria, destacan, por su particularidad, las comarcas naturales de Liébana y de Reinosa (Campoo-Los Valles), por encontrarse, respectivamente, en los Picos de Europa y en la cuenca del Ebro. Aunque su estatuto lo permite, Murcia no cuenta con una división comarcal arraigada, y quizá sea la comunidad que menos la necesite, ya que posee los términos municipales de mayor extensión media de España ${ }^{4}$. No obstante, Murcia es, junto con Asturias, la única comunidad autónoma peninsular que utiliza para sus elecciones autonómicas una demarcación territorial superior al municipio e inferior a la provincia, siendo cinco sus circunscripciones electorales (Murcia, Cartagena, Lorca, Caravaca y Yecla) (figura 1).

4. Entre ellos, hay ocho (Lorca, Moratalla, Jumilla, Murcia, Caravaca, Mula, Yecla y Cartagena), con un término más grande que la mayoría de las comarcas litorales valencianas y catalanas. 


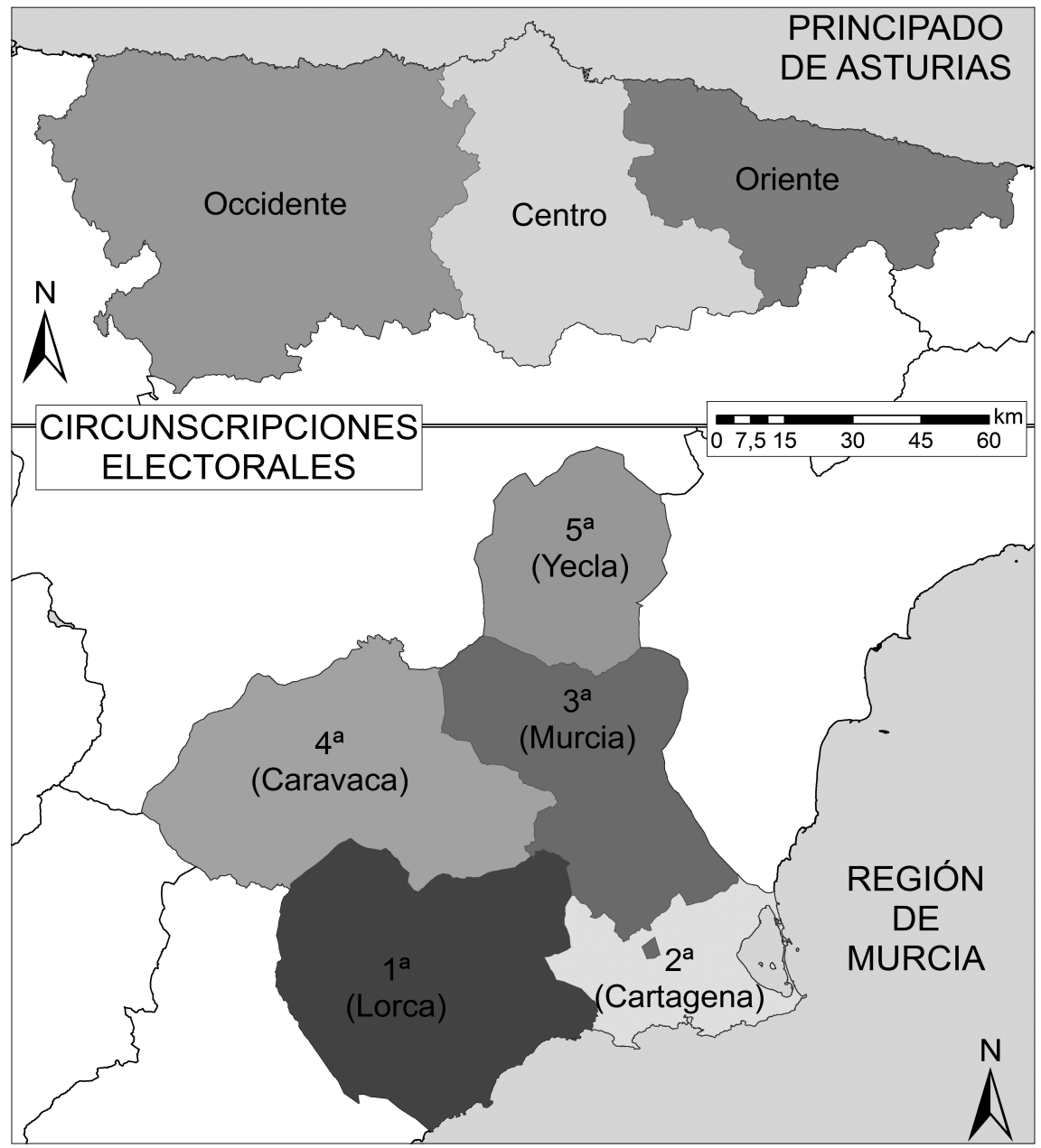

Figura 1. Circunscripciones electorales en Asturias y Murcia.

Fuente: Ley 14/1986, de 26 de diciembre, sobre régimen de elecciones a la Junta General del Principado de Asturias, y Ley 2/1987, de 12 de febrero, electoral de la Región de Murcia.

Los estatutos de Castilla-La Mancha y Extremadura también permiten crear una organización territorial en comarcas ${ }^{5}$. Sin embargo, hay una serie de obstáculos que impiden el avance del proceso comarcalizador, como son las numerosas mancomunidades que ya prestan diferentes servicios a los municipios y la sólida identificación con el ámbito provincial y municipal.

5. Se da la circunstancia de que en Castilla-La Mancha existe la comarca natural más grande de España, La Mancha, con una extensión mayor que la de cualquier provincia y que muchas comunidades autónomas. 
Desde Castilla y León, donde la institución provincial goza de gran tradición histórica, puesto que se remonta a la baja edad media, se exportó el actual modelo provincial español a la periferia durante el siglo xix. Su profundo enraizamiento casa mal con cualquier intento comarcalizador. A pesar de ello, Castilla y León es una de las cuatro comunidades donde podemos encontrar comarcas administrativas oficiales, aunque solo ha definido una: El Bierzo.

A continuación, vamos a mostrar los diferentes proyectos de comarcalización - exitosos o fallidos - llevados a cabo hasta la fecha en las principales comunidades autónomas de la periferia española. Para complementar los resultados del proceso de comarcalización en cada territorio estudiado, mostraremos un mapa con las divisiones comarcales más significativas. Además, en este mismo apartado, mostraremos la discusión de los resultados en cada uno de los procesos de comarcalización analizados.

\subsubsection{Andalucía: diversos proyectos sin implementar}

El artículo 97.2 del actual Estatuto de Autonomía para Andalucía, aprobado en 2007, contempla la posible creación de comarcas reguladas mediante una ley del Parlamento andaluz, que establecería sus competencias. No obstante, hay diversos factores que han obstaculizado este proceso, como son la existencia de mancomunidades; la sólida identificación con la provincia y el municipio, y la escasa tradición comarcal en la depresión del Guadalquivir, donde los espacios abiertos no contribuyen a la aparición de este tipo de demarcaciones, lo contrario que sucede en la montañosa parte oriental de Andalucía.

Los diferentes intentos de comarcalización de Andalucía han seguido dos caminos principales: por un lado, los que pretendían configurar comarcas homogéneas desde el punto de vista histórico, socioeconómico, demográfico y físico; por otro, los que querían definir comarcas funcionales a partir de un centro polarizador que ejerce su influencia sobre su entorno inmediato (Cano, 1984). Antes de 1980, se habían llevado a cabo diversas delimitaciones comarcales (áreas comerciales y de servicios, comarcas naturales y geográficas, comarcas homogéneas, etc.) que, aunque de carácter sectorial y dirigidas a satisfacer las necesidades del Estado, tuvieron cierta influencia en trabajos posteriores de comarcalización (Pezzi, 1982; Cano, 1989).

En 1983, se desarrolló el Proyecto de Comarcalización para Andalucía, consistente en 122 ámbitos y 127 ciudades, que pretendía definir unas áreas funcionales para racionalizar la prestación de los servicios públicos y la planificación urbana (Compán, 1983: 184). Este proyecto, que presentaba ciertas deficiencias metodológicas, fracasó, en gran medida, por la falta de voluntad política y la fuerte oposición de los municipios. Poco después, en 1986, la Dirección General de Ordenación del Territorio presentó el Sistema de Ciudades de Andalucía, consistente en 4 rangos urbanos: Sevilla, como capital de Andalucía; 9 centros subregionales (las otras capitales de provincia más Algeciras y Jerez); 18 centros urbanos intermedios, y 99 centros urbanos básicos. Este nuevo mapa comarcal andaluz había de servir de modelo para la descentralización administrativa sectorial, aunque solo fue relevante en la ejecución 


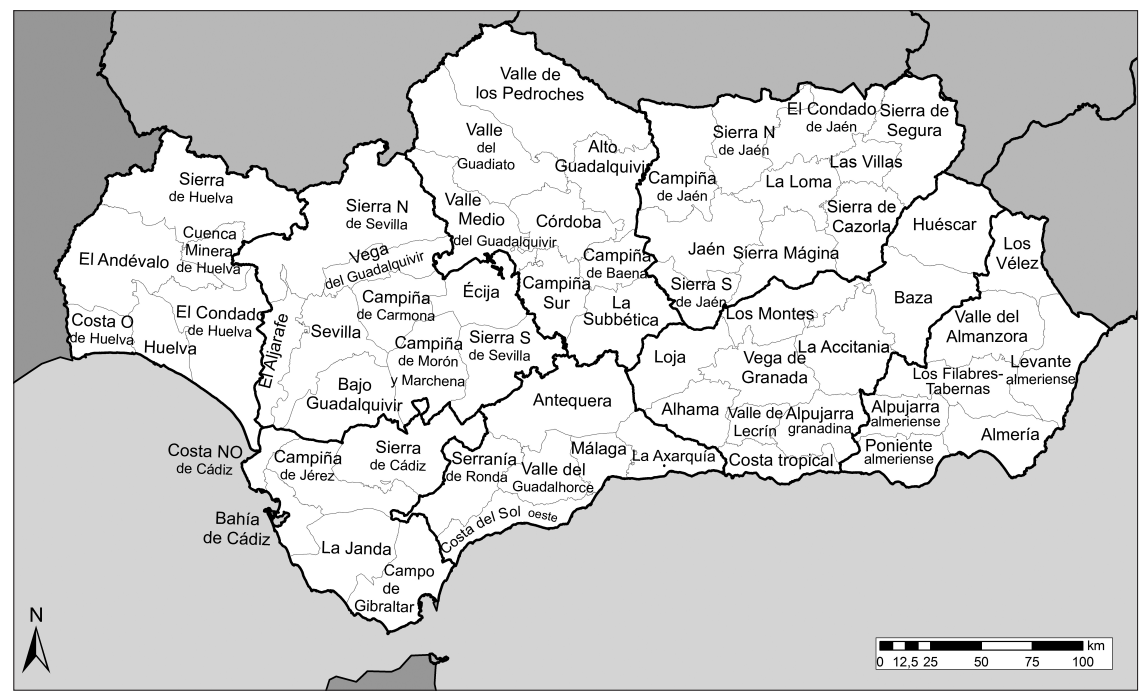

Figura 2. Comarcas (no oficiales) de Andalucía.

Fuente: Consejería de Turismo y Deporte de la Junta de Andalucía (BOJA del 27 de marzo de 2003).

de la red principal de carreteras andaluzas (Cano, 1989; Copano y Ventura, 2013). El Sistema de Ciudades de Andalucía derivó, posteriormente, en una propuesta zonificadora incluida en las Bases para la Ordenación del Territorio de Andalucía (1990), que, finalmente, no tuvo repercusiones efectivas en las políticas desarrolladas más adelante.

Los estudios comarcales andaluces resurgieron una década más tarde por una doble vía. Por una parte, con el Informe de desarrollo territorial de Andalucía, coordinado por el profesor Zoido (2001), que pretendía transferir a una base comarcal el objetivo de erradicar las desigualdades territoriales. Este proyecto dividía la comunidad autónoma en 63 unidades, ajustadas a los límites provinciales según determinaba el anterior Estatuto de Autonomía y delimitadas a partir de criterios principalmente funcionales y de voluntad política intermunicipalista (Benabent, 1998). Por otra parte, aparece, en 2002, la propuesta de comarcalización del profesor Cano en el tomo x de la obra Conocer Andalucía: Gran Enciclopedia Andaluza del Siglo XXI, resultado de los trabajos del grupo de investigación Estudios Geográficos Andaluces sobre jerarquización de núcleos en dicha comunidad autónoma y análisis de los desplazamientos sobre el territorio andaluz para adquisición de productos y obtención de servicios (Cano, 2002).

En 2003, la Consejería de Turismo y Deporte de la Junta de Andalucía (BOJA del 27 de marzo de 2003) elaboró un mapa comarcal, muy próximo a los dos anteriormente referidos, donde se definían 62 espacios geográficos con unas características naturales, económicas y sociales comunes (ver figura 2). 
Aunque dichos espacios geográficos no tienen funcionalidad alguna, este es uno de los mapas comarcales de Andalucía más difundidos en la actualidad.

En 2006, se aprobó, mediante el Decreto 206/2006, el Plan de Ordenación del Territorio de Andalucía, cuya finalidad era adecuar su organización territorial a las necesidades y potencialidades del momento, además de diseñar una estrategia territorial andaluza global para corregir los desequilibrios internos. El modelo propuesto creaba distintas unidades basadas tanto en el sistema de ciudades con sus áreas respectivas de influencia, como por la homogeneidad física y funcional. Estos espacios debían de ser referentes básicos, por un lado, para el desarrollo de estrategias territoriales relacionadas con la gestión del suelo, el uso de recursos naturales, el paisaje o la prevención de riesgos, y, por otro, para contextualizar los grandes sistemas regionales (ciudades, transportes, sistemas hidráulico y energético, patrimonio). Esta delimitación comarcal, eminentemente funcional y vertebradora del territorio, presenta como gran novedad la ruptura de los límites provinciales ${ }^{6}$ y municipales ${ }^{7}$ (Copano y Ventura, 2013). Sin embargo, el actual contexto de crisis económica ha impedido implementar al completo el ambicioso Plan de Ordenación del Territorio de Andalucía, de 2006, cuyos planes subregionales no se están ajustando, además, a las unidades territoriales previamente establecidas.

\subsubsection{Valencia: comarcas funcionales y estadisticas}

El Estatuto de Autonomía de Valencia, promulgado en 1982 y reformado en 2006, afirma, en su artículo 65, que una ley de Las Cortes podrá determinar la división en comarcas, que son circunscripciones administrativas de la Generalitat y entidades locales para la prestación de servicios y la gestión de asuntos comunes. Sin embargo, las posibilidades que brinda el Estatuto para crear una nueva organización territorial no han sido apenas aprovechadas.

En la historia de la actuación de las instituciones autonómicas valencianas en referencia a esta cuestión, puede distinguirse un primer momento, entre 1982 y 1987, en el cual los políticos aparentemente tenían un verdadero interés en sacar adelante la comarcalización - respondiendo al espíritu del Estatutoe identificaban autonomía con comarcalización, asumiendo que comarcalizar ayudaba a la integración y a la recomposición natural de las tierras valencianas (Membrado, 2013: 17). En 1985, se creó la Conselleria de Administración Pública, con Vicent Soler al frente, que poseía una decidida voluntad de impulsar la comarcalización. En 1986, se consolidó el único ente territorial de tamaño medio entre la provincia y el municipio: el Consell Metropolità de l'Horta (CMH). Su ámbito geográfico era la ciudad de Valencia y otros 43 municipios de la comarca de l'Horta, y su papel era la planificación territorial metropolitana (Burriel, 2009). Sin embargo, los enfrentamientos políticos lo hicieron

6. Crea, por ejemplo, la comarca de las Serranías de Cádiz y Ronda, a caballo entre dos provincias.

7. Divide, por ejemplo, el extenso municipio de Jerez en dos unidades: una integrada en las Serranías de Cádiz y Ronda, y otra en el sistema urbano de la Bahía de Cádiz. 
inviable y, en 1999, fue suprimido por el Gobierno de Eduardo Zaplana. Sus competencias fueron asumidas por dos nuevas entidades metropolitanas: EMTRE (de tratamiento de residuos) y EMSHI (de servicios hidráulicos) ${ }^{8}$.

Por lo que respecta a la comarcalización, se plantearon diversas propuestas. La más exitosa fue la de Joan Soler de 1970 (Piqueras y Membrado, 1995: 342344; Membrado, 2013: 14-16), que dividía el territorio en 32 comarcas, en su planteamiento original, que luego fue retocada hasta llegar a 34 comarcas. Sin embargo, jamás llegó a implementarse a nivel oficial, ya que hubo fuertes presiones - sobre todo desde las diputaciones- que impidieron continuar con el proceso de comarcalización iniciado en 1982. En 1987, su principal valedor, Vicent Soler, optó por dimitir ante la imposibilidad de avanzar. Con su sustituto, Joaquín Azagra (1987-1989), la cuestión comarcal se relegó a un segundo plano y se optó por la idea de comarcalizar desde abajo, es decir, que debían ser los propios municipios quienes debían tener la iniciativa de mancomunarse en unidades más o menos comarcales.

Por otro lado, en 1988, la Generalitat Valenciana publicó una comarcalización — no oficial - de referencia con tres niveles distintos de desagregación: las llamadas demarcaciones territoriales homologadas (DTH). Las DTH de tercer nivel coincidían con las tres provincias. Las 16 DTH de segundo nivel partían de las comarcas de Joan Soler, agregando las menos pobladas a sus vecinas, con el fin de que todas fueran viables demográficamente (figura 3). El papel de estas consistía en coordinar en una única división territorial las áreas de actuación funcional (áreas sanitarias, judiciales, escolares, agrarias, etc.). Las 34 DTH de primer nivel seguían la propuesta de Joan Soler y servían como referencia para el proceso de construcción desde abajo de las comarcas a partir de las mancomunidades: se pretendía incentivar particularmente aquellas mancomunidades de interés comarcal que se aproximasen al modelo de las DTH de tercer nivel (figura 3). Sin embargo, las iniciativas de apoyo a las mancomunidades fueron paralizadas por el conseller Emèrit Bono (1989-1993), con el que se inició una etapa marcada por un progresivo desinterés por las comarcas, acentuada con la llegada al poder de los populares Zaplana, Olivas, Camps y Fabra (Membrado, 2013: 20).

Cabe remarcar que la Generalitat Valenciana propuso recientemente una estrategia territorial que debería guiar el crecimiento sostenible de la Comunidad Valenciana hasta 2030 en materias como, entre otras, el agua, el suelo, el paisaje, la vivienda, el patrimonio ambiental, el mundo rural, las infraestructuras y la innovación y la dinamización económicas. Esta estrategia territorial definía como adecuados para la gestión y la planificación territorial supramunicipal una serie de ámbitos territoriales intermedios denominados áreas funcionales, delimitadas a partir de criterios como los desplazamientos de personas, la expansión urbana, la prestación de servicios supramunicipales y los corredores de transporte público, y capaces de articular el territorio de manera integral y ordenada.

8. Véase <http://ssweb.seap.minhap.es/REL/frontend/inicio/areas_metropolitanas >. 


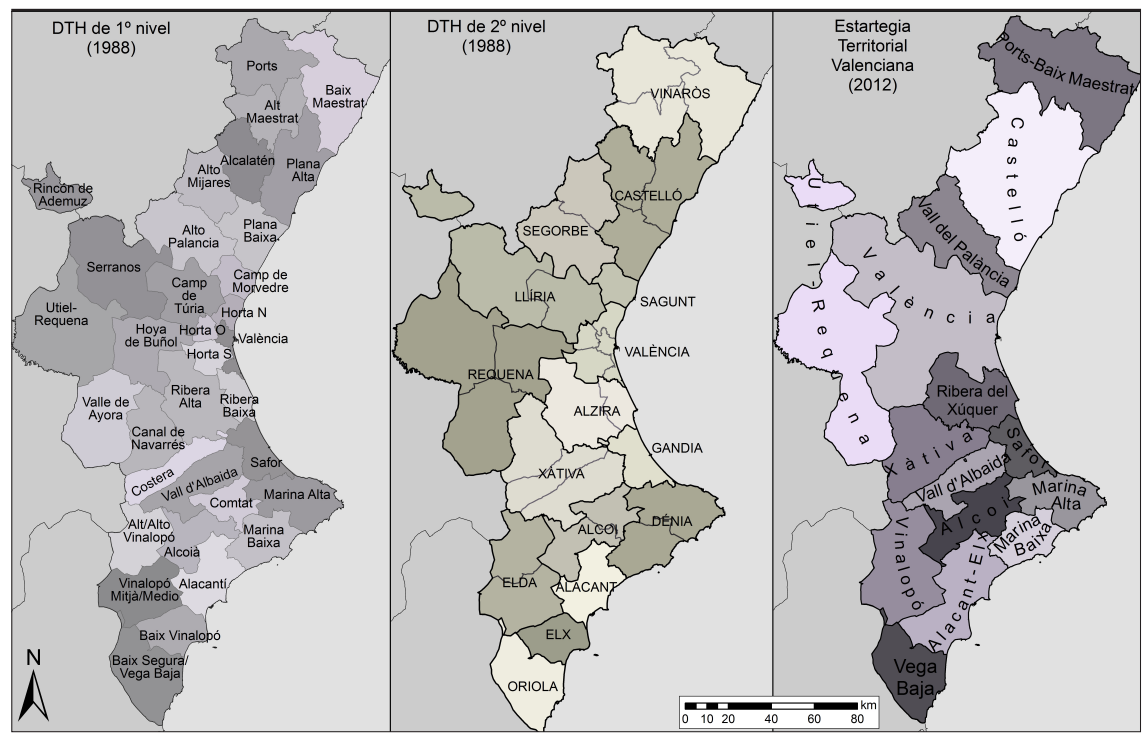

Figura 3. Valencia: demarcaciones territoriales homologadas de primer y segundo nivel (1988) y áreas funcionales de la Generalitat (2012).

Fuente: mapas izquierda y centro: propuesta de demarcaciones territoriales homologadas (1988) (Conselleria de Administración Pública, Decreto 170/1985, de 28 de octubre, del Consell de la Generalitat Valenciana); mapa derecha: Muñoz y Doménech (2012).

Se trata de 15 áreas funcionales — diseñadas por el geógrafo Vicent Doménech (Muñoz y Doménech, 2012) — que, como las 16 DTH de segundo nivel, pretende que cada ámbito territorial tenga un umbral mínimo de población (unos 100.000 habitantes) que la haga viable funcionalmente, a diferencia del modelo de Joan Soler (DTH de primer nivel), que opta por comarcas de dimensiones territoriales similares donde exista un sentimiento de adhesión comarcal entre sus habitantes. Cabe remarcar que, en este mismo documento sobre estrategia territorial (Muñoz y Doménech, 2012), se sigue hablando de las 34 comarcas o DTH de primer nivel, pero no como ámbitos de actuación territorial, sino tan solo a efectos estadísticos.

La propuesta de 15 áreas funcionales (2012), comparada con las 16 DTH de segundo nivel (1988), es novedosa en dos aspectos. En primer lugar, crea sendas macroáreas funcionales para cada uno de los dos grandes espacios metropolitanos valencianos (el de Alicante-Elche y el de la ciudad de Valencia, a la que se incorpora toda la cuenca del Turia y el área de Buñol-Chiva, que carecen de una auténtica cabecera comarcal). En segundo lugar, fusiona el Camp de Morvedre (provincia de Valencia) con el Alto Palancia y parte del Alto Mijares (ambos en la provincia de Castellón), en aras de primar la funcionalidad sobre el hasta ahora intocable límite provincial (figura 3). 


\subsubsection{País Vasco: áreas funcionales y cuadrillas alavesas}

El País Vasco cuenta con el mismo número de áreas funcionales que el País Valenciano. Estas áreas funcionales son el marco de referencia supramunicipal para seguir las Directrices de Ordenación del Territorio (DOT) del Gobierno Vasco por lo que respecta a políticas medioambientales, recursos naturales, paisaje, espacios urbanos, industriales y rurales, e infraestructuras y equipamientos del patrimonio histórico y cultural. El diseño de las áreas funcionales establece una serie de cabeceras comarcales con el fin de consolidar una red de ciudades medias a partir de las cuales se presten servicios a toda el área funcional y se creen nuevas opciones de desarrollo, donde se integren armónicamente los espacios urbanos y rurales, y donde la ordenación del territorio se lleve a cabo de una manera próxima a los ciudadanos. Con la institucionalización de dichas cabeceras y sus áreas de influencia respectivas, se pretende, por lo tanto, el desarrollo coordinado de la comunidad autónoma vasca. Esta política se fundamenta además en criterios de interconexión e integración, de tal manera que los planes territoriales de los municipios no se elaboren de forma independiente entre sí, sino a escala comarcal, para conseguir objetivos coherentes. El diseño y la potenciación de estas áreas intermedias supramunicipales forman parte de la estrategia de consolidación y desarrollo de la llamada ciudad-región global vasca (Alberdi, 2004: 10). Este modelo de ciudad-región global se caracteriza por las notables relaciones económicas con el exterior — de ahí el adjetivo global-y por referirse a una región altamente urbanizada y caracterizada por un sistema polinuclear de ciudades interdependientes y, por lo tanto, complementarias - de ahí el nombre compuesto de ciudad-región-. Por su alta propensión exportadora y por su sistema urbano policéntrico, Euskadi puede considerarse una ciudad-región global.

Las áreas funcionales vascas se han rediseñado en 2014 con el fin de integrar eficientemente el sistema urbano polinuclear de su territorio. Para el diseño de dichas áreas, al igual que para las áreas funcionales de Valencia, era necesario contar con un umbral mínimo de población, de modo que fuera viable dotarlas de servicios y existiera demanda suficiente de los mismos. Esto explica las dimensiones desiguales de dichas áreas, con notables diferencias entre la demarcación de Álava Central y las comarcas de la vertiente cantábrica (figura 4). Además, otros criterios para la delimitación han sido la homogeneidad fisiográfica, el sentimiento de pertenencia de sus habitantes y las relaciones de dependencia y complementariedad.

Los factores demográficos y económicos han primado en la configuración de las nuevas áreas funcionales vascas sobre los factores históricos. Así, estas no se ajustan ni a los límites de los tres territorios históricos (Dávila, 2012: 189) ni a las siete comarcas administrativas de Álava (figura 4). Dichas comarcas o cuadrillas, delimitadas según la norma foral de Álava 63/1989, de 20 de noviembre, están dotadas de órganos de gobierno (juntas de cuadrilla) ${ }^{9}$ con

9. En la cuadrilla de Vitoria-Gasteiz, el Ayuntamiento asume directamente las competencias que en las demás cuadrillas alavesas asumen las juntas de cuadrilla. 


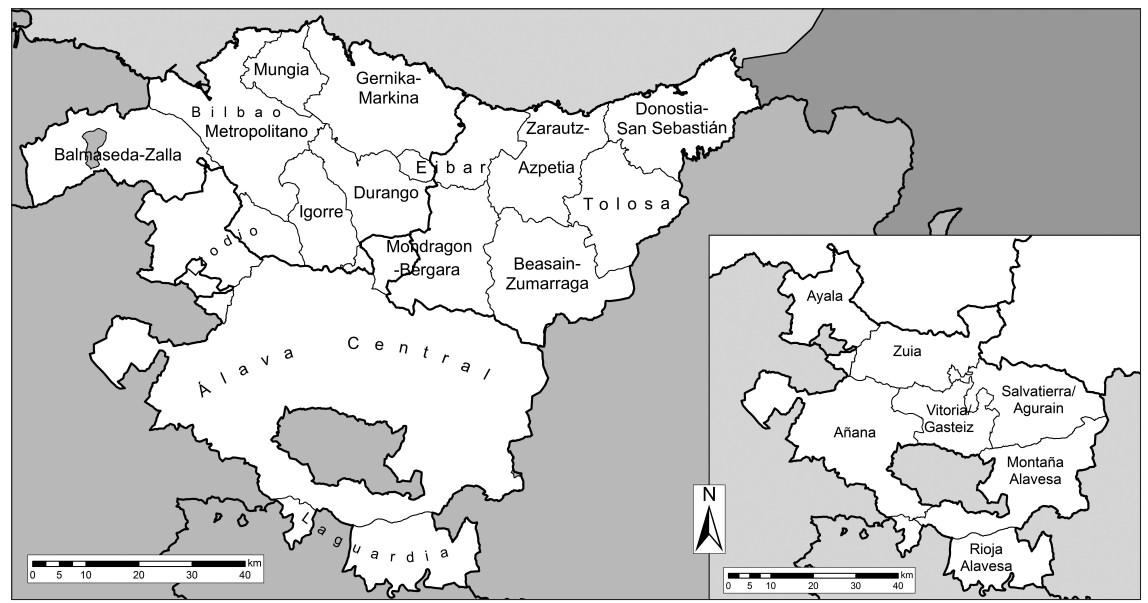

Figura 4. Euskadi: áreas funcionales del Gobierno Vasco (2014) y cuadrillas alavesas (derecha).

Fuente: Directrices de Ordenación del Territorio (DOT) del Gobierno Vasco (izquierda) y Norma Foral 63/89, de 20 de noviembre de 1989, de la Diputación de Álava (derecha).

competencias en materia de recogida de residuos, promoción turística, dinamización sociocultural, servicios de información al consumidor y de archivo y gestión documental, y políticas de juventud.

\subsubsection{El caso particular de El Bierzo y el proceso fallido en Galicia}

Castilla y León ha optado excepcionalmente por la creación individualizada de una sola comarca: El Bierzo. Según el capítulo ir de la Ley sobre la comarca de El Bierzo, este territorio podrá ejercer las competencias — transferidas desde la junta castellanoleonesa- sobre ordenación del territorio y urbanismo, sanidad, servicios sociales y cultura y deporte, entre otras. El reconocimiento de El Bierzo como comarca administrativa por las Cortes de Castilla y León (Ley 1/1991) responde al deseo de canalizar el sentimiento diferencial de esta comarca (Quintana, 1993: 141), que se encuentra a medio camino entre León y Galicia, y en cuya zona occidental se habla gallego (figura 5). Este sentimiento berciano diferenciado deriva en última instancia de la peculiar fisiografía de dicho territorio dentro de su comunidad autónoma, ya que se encuentra a menor altitud y está más influida por la humedad atlántica que el resto de Castilla y León. De hecho, El Bierzo no forma parte de la cuenca hidrográfica del Duero, como la mayor parte de Castilla y León, sino de la del Miño-Sil, la misma que riega el sur y el este de Galicia. Estos rasgos diferenciales fisiográficos y culturales fueron los detonantes de la creación de la efímera provincia de El Bierzo en 1822 (Burgueño, 1995: 17-18) y de la actual comarca berciana.

Por lo que respecta a las comarcas de Galicia, fueron previstas en el Estatuto de 1980, promulgadas en 1996 y promovidas por el pensamiento galleguista, 


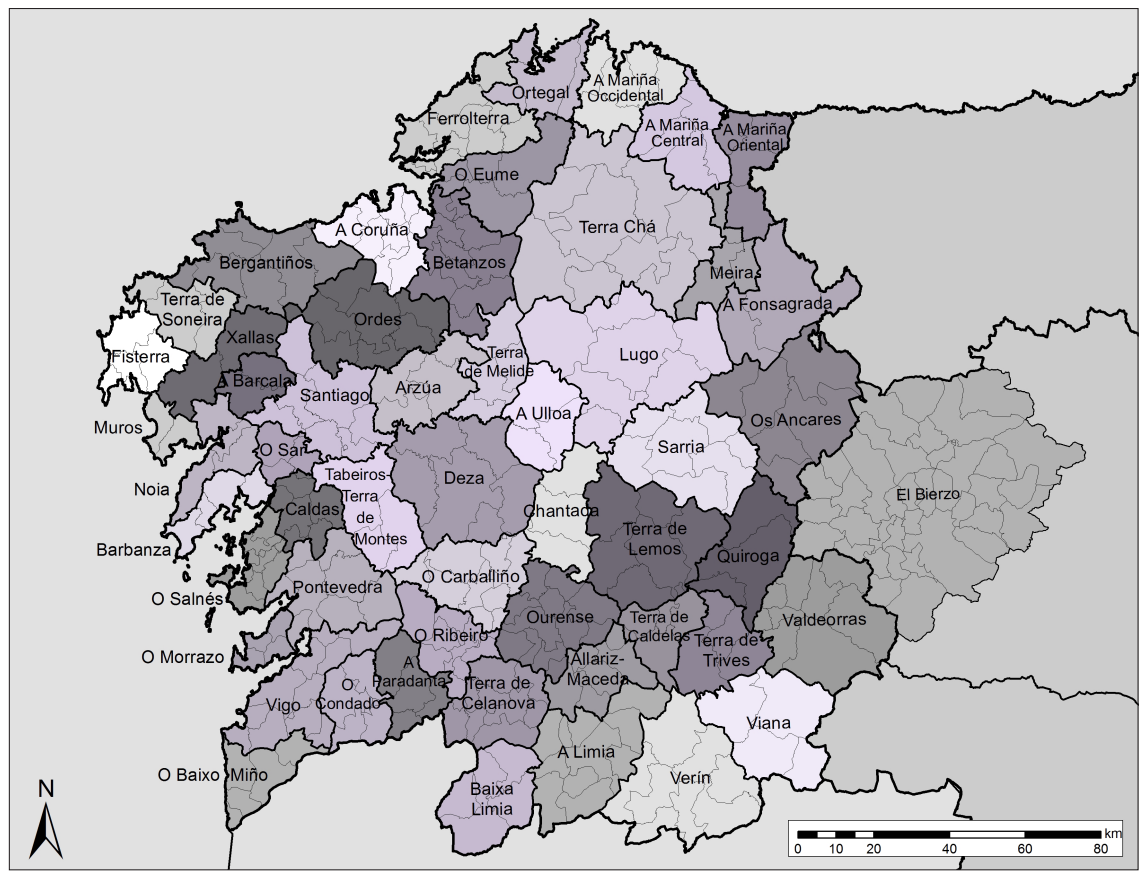

Figura 5. Mapa comarcal de Galicia y El Bierzo (León).

Fuente: Ley 7/1996, de 10 de julio, de desarrollo comarcal de Galicia, y Ley 1/1991, que crea y regula la comarca de El Bierzo (LCyL 1991\95).

que las defendía en tanto que territorios mucho mejor ajustados a la dinámica económico-funcional del país y, por lo tanto, más proclives a favorecer el desarrollo territorial que las provincias o los municipios.

Entre los especialistas que iniciaron el debate comarcal, cabe destacar a los geógrafos Precedo (1974, 1987) y Souto (1983), cuyas propuestas de comarcalización sirvieron de referencia para el diseño del mapa (figura 5) que acompañaba a la Ley de comarcalización de Galicia aprobada en 1996. Sin embargo, la viabilidad de dicha ley fue cuestionada desde ese mismo momento y frenada tanto por la oposición, que denunciaba que el plan comarcal se quedaba corto, como por las diputaciones, temerosas de perder las competencias que poseían (Lois y Aldrey, 2010: 593) ${ }^{10}$.

Ante las presiones en su contra, a las comarcas no se les transfirió competencia alguna, y fueron reorientadas como meras gestoras de proyectos (normalmente europeos) encaminados a la promoción de territorios desfavorecidos (Precedo, 2004). De esta manera, la comarcalización gallega se enfocó princi-

10. Prestarían servicios (alumbrado, cementerio, recogida de residuos, limpieza viaria, abastecimiento de agua, alcantarillado, etc.) a los municipios incapaces de proveerse de los mismos. 
palmente al impulso del desarrollo endógeno y así, entre las comarcas creadas, las más dinámicas fueron las de base rural, con límites bien definidos, como O Deza, Ordes y A Mariña Oriental, que cuentan además con una clara cabecera comarcal (Lalín, Ordes y Ribadeo, respectivamente). Allí se gestionaron notables proyectos de desarrollo local y se impulsó la creación de fundaciones comarcales compuestas por representantes de la Xunta, los ayuntamientos y asociaciones privadas. Sin embargo, el pragmatismo inmovilista y la coalición de intereses contrarios a la comarcalización terminó por quitarle todo el sentido a la misma: las fundaciones comarcales iniciaron su progresiva disolución, culminada en 2010, y los proyectos europeos fueron asignados a otras entidades. Lo que resta en la actualidad del proyecto inicial de comarcalización es solo el mapa, que sigue presente en bibliotecas y despachos (figura 5), y una ley que no ha sido derogada pero sí vaciada de contenido (Lois y Aldrey, 2010: 601).

Hay que remarcar que, tras el fracaso del proyecto de comarcalización de 1996, el discurso galleguista sobre la organización territorial de Galicia se renovó a partir de mediados de la primera década del siglo XXI, proponiendo la conveniencia de superar el marco provincial de manera gradual y asimétrica, creándose en primer lugar unas áreas metropolitanas que saliesen del ámbito competencial de las diputaciones, mientras que el medio rural continuaría en manos de la Administración provincial (Paül y Pazos, 2009: 228). El primer paso en esta nueva organización territorial asimétrica se dio en 2012, con la creación, mediante una ley autonómica, de un ente local supramunicipal: el Área Metropolitana de Vigo y Pontevedra (si bien todavía no figura en el registro de entidades locales del Estado (Ministerio de Hacienda y Administraciones Públicas, s. f. $)^{11}$, integrada por estas dos ciudades más las de sus áreas de influencia respectivas y destinada a la planificación territorial, coordinación de diversos servicios y mejora de la eficacia de las inversiones públicas. El segundo proyecto de área metropolitana gallega, todavía en estudio, incluiría la región urbana del golfo ártabro, formada por las áreas de A Coruña y Ferrol.

\subsubsection{Aragón: comarcas para corregir los desequilibrios territoriales}

Aragón aprobó una nueva organización territorial en 2006, que estaba fundamentada en la comarca, para hacer frente a las dificultades que tienen los pequeños municipios para la prestación de servicios. El proceso migratorio del siglo $\mathrm{xx}$ ha generado un envejecimiento y un despoblamiento alarmantes de la población rural de Aragón (711 de sus 731 municipios cuentan con menos de 5.000 habitantes), mientras que la macrocefalia de Zaragoza respecto a su comunidad autónoma no es menos llamativa: la mitad de todos los aragoneses $\mathrm{y}$ aragonesas viven en esa ciudad.

El modelo de comarcalización aragonés pretende corregir estos desequilibrios y, para ello, se considera imprescindible mantener el territorio vivo. Dicho modelo se fundamenta en el principio de que la cercanía en la toma de decisiones supone una mejor asignación de los recursos para la prestación

11. Véase <http://ssweb.seap.minhap.es/REL/frontend/inicio/areas_metropolitanas>. 


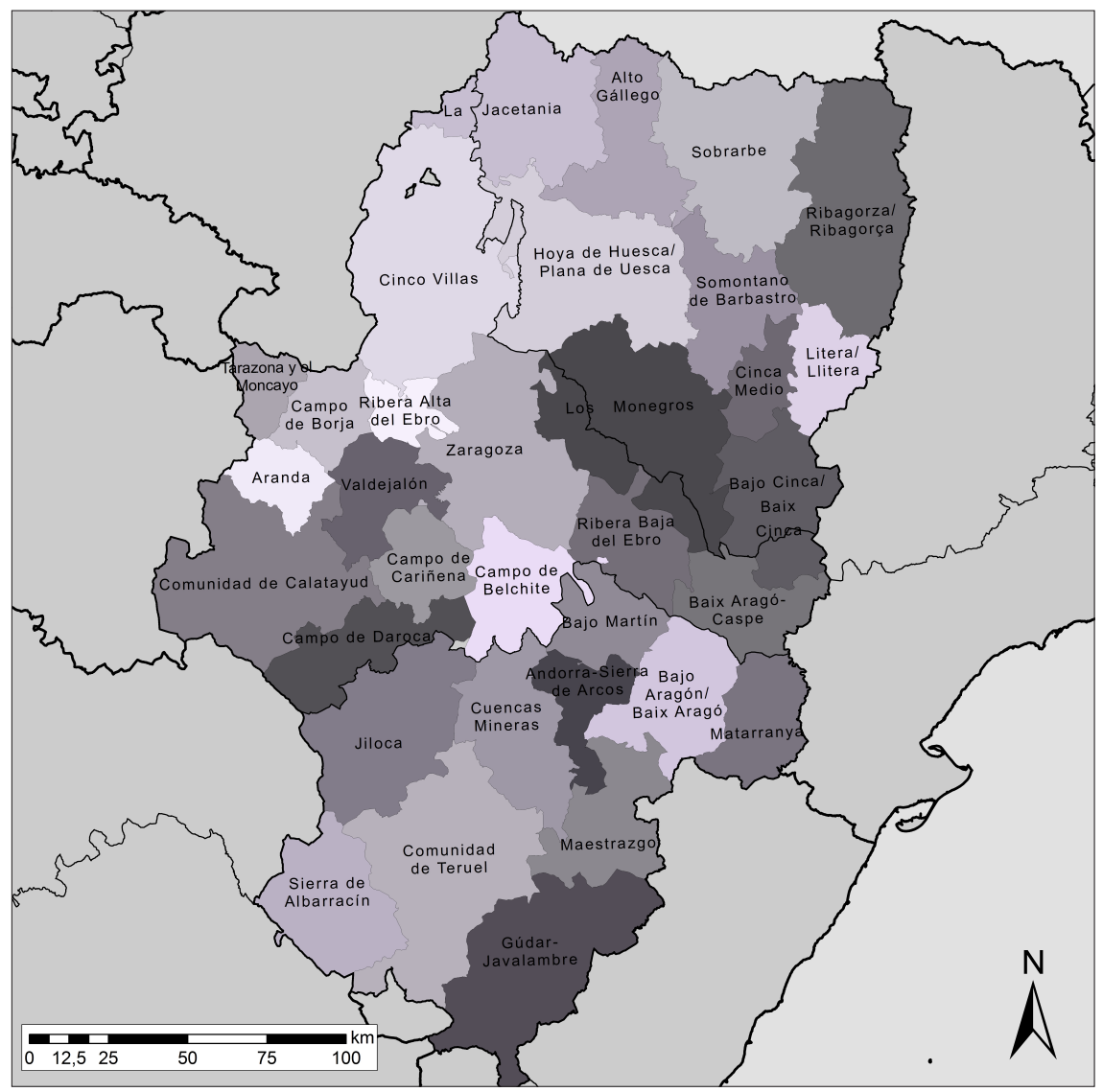

Figura 6. Mapa comarcal de Aragón (con límite provincial).

Fuente: Ley de comarcalización de Aragón, decreto legislativo 1/2006, de 27 de diciembre, del Gobierno de Aragón.

de servicios. Su objetivo es que todos los ciudadanos, independientemente de donde residan, puedan desarrollar nuevas actividades económicas en el territorio, mejorando su calidad de vida y frenando la emigración y el despoblamiento (Infante, 2010: 60). Para delimitar las comarcas aragonesas, a partir de una serie de criterios (existencia de una cabecera, tradición histórica, de tipo económico, etc.), se elaboraron una serie de propuestas, siendo la del geógrafo Vicente Bielza (1992) la que sirvió de base para el mapa que finalmente fue aprobado por las Cortes de Aragón en 1996. Dicho mapa, que consta de 33 comarcas, muestra un indudable espíritu rupturista, que se refleja en el hecho de que no coincide con los límites provinciales (al menos entre Zaragoza y Huesca) (figura 6). 
El proceso de comarcalización de Aragón ha implicado la descentralización administrativa, es decir, la transferencia de competencias desde la Administración regional hasta la comarcal. Además, cada comarca recibe las mismas competencias, que, para evitar la duplicidad de atribuciones y gastos, dejan de estar asignadas a la Diputación General de Aragón. Entre estas competencias transferidas a las comarcas, hay 19 materias de gestión, entre las cuales ya se han transferido las de acción social; cultura, patrimonio cultural y tradiciones populares; deporte; juventud; promoción del turismo; protección civil y extinción de incendios, y servicio de recogida y tratamiento de residuos sólidos urbanos. El resto de competencias susceptibles de ser gestionadas por las comarcas serían la ordenación del territorio y urbanismo, los transportes, la protección del medio ambiente, la sanidad y la salubridad públicas, la acción social, la agricultura, ganadería y montes, la artesanía, la protección de los consumidores y usuarios, la energía, la promoción y la gestión industrial, las ferias y los mercados comarcales, y la enseñanza (Barberán, 2003: 62; Infante, 2010: 66-67).

Por el momento, 32 de las 33 comarcas ya gestionan las competencias que se les han transferido desde la Diputación General de Aragón. Quedan por transferir las competencias a la más compleja de todas: la comarca de Zaragoza, donde los límites no se ajustan estrictamente a la realidad metropolitana cambiante de la capital aragonesa (figura 6). Para evitar agravios hacia los pueblos de esta comarca sin competencias, provisionalmente se ha constituido la mancomunidad central de interés comarcal, integrada por los municipios de esta comarca salvo la capital, de manera que dichos municipios también puedan beneficiarse de los fondos comarcales en igualdad de condiciones (Infante, 2010: 64-65).

Todavía es pronto para valorar los resultados de este proceso en el desarrollo territorial de Aragón, ya que las competencias relacionadas con el fomento de la agricultura, la industria y el comercio, así como con el desarrollo endógeno del territorio, todavía no se han transferido. No obstante, no hay duda de que Aragón es, junto con Cataluña, el territorio que más decididamente ha apostado por el desarrollo de las comarcas.

\subsubsection{Cataluña: municipio, comarca, veguería y área metropolitana}

En Cataluña, la comarca posee un gran arraigo histórico y la división territorial propia está diseñada al margen de la división provincial, no solo porque algunas comarcas se encuentran a caballo entre dos provincias (figura 7), sino también porque se pretende superar la división provincial mediante la creación de un ente supracomarcal — la veguería - que sustituya a la provincia.

En 1987, se aprobó la nueva Ley de organización territorial (LOT) de Cataluña, de la que derivarían cuatro leyes referidas, respectivamente, al municipio, a la comarca, a la diputación y a la conurbación barcelonesa. La primera ley, referida al mapa municipal, amparaba la fusión de municipios y la corrección de anomalías tales como enclaves o continuos urbanos (Burgueño, 2001: 197). La segunda reinstauraba el mapa comarcal diseñado por una comisión presidida por el geógrafo Pau Vila en 1932 (Lluch y Nel·lo, 1983 y 1984). Este mapa 


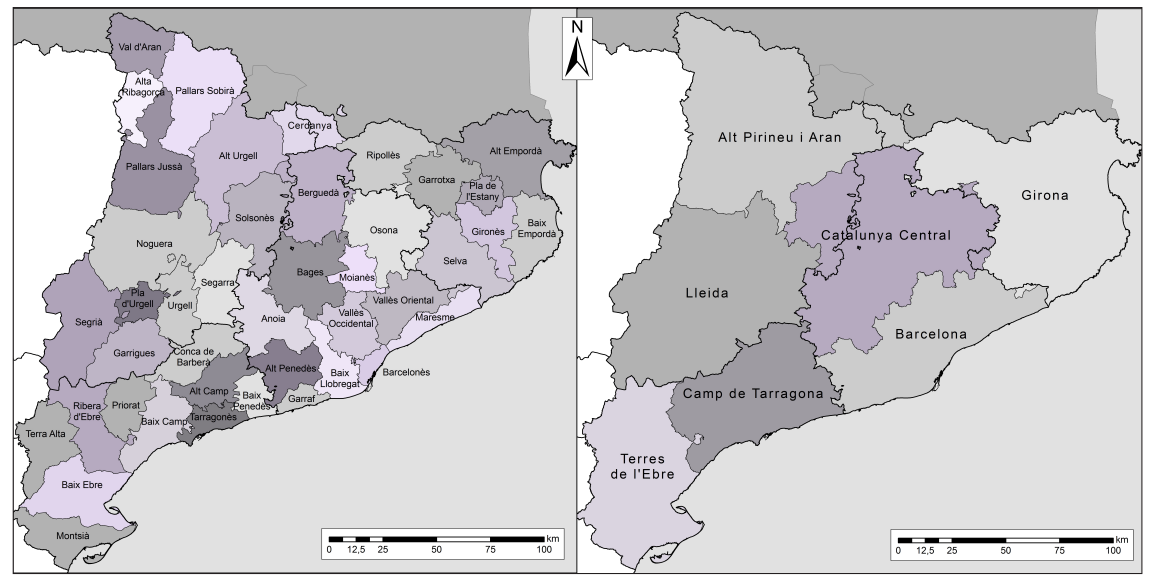

Figura 7. Comarcas (izquierda) y veguerías (derecha) de Cataluña, con límites provinciales. Fuente: Institut Cartogràfic de Catalunya.

comarcal había estado vigente en Cataluña entre 1936 y 1939. Posteriormente, en 1988, se hicieron algunos cambios puntuales, creando también tres nuevas comarcas (Pla de l'Estany, Pla d'Urgell y Alta Ribagorça), con lo que estas sumaban un total de 41 (Burgueño, 2003). En 1990, se cambió la adscripción comarcal de algunos municipios y, en 2015, se estableció una nueva comarca (el Moianès) (figura 7). La segunda ley de la LOT, además, creaba los consells comarcals, definidos como entes locales cuyas funciones coincidirían provisionalmente con las de las diputaciones, mientras estas últimas no desapareciesen (Burgueño, 2001: 197). La tercera ley promovía la fusión de las cuatro provincias en una sola: la de Cataluña. Esta nueva provincia absorbería las diputaciones, como ya había pasado en las comunidades uniprovinciales y en Canarias, y, al mismo tiempo, sería el punto de partida para adoptar una nueva división territorial supracomarcal en un mínimo de cinco regiones o veguerías, destinada solo a la organización periférica de la Generalitat. La cuarta ley disolvía la Corporació Metropolitana de Barcelona (CMB) (1974-1987), controlada por el PSC y enfrentada a la Generalitat de CiU, y creaba dos nuevos entes metropolitanos (uno para el medio ambiente y otro para el transporte) de ámbito territorial no coincidente (Burgueño, 2001: 197).

Tras varias décadas de funcionamiento de la LOT, los resultados han sido poco halagüeños. Por lo que respecta a la primera ley, el mapa municipal no solo no se ha reducido, sino que se han producido ocho nuevas segregaciones.

En cuanto a la segunda ley, las competencias que son susceptibles de ser desarrolladas por las comarcas catalanas son las de ordenación del territorio y urbanismo, sanidad, servicios sociales, cultura, deporte, enseñanza, salubridad pública y medio ambiente. Pero, contrariamente a lo que pasa en Aragón, en Cataluña la comarca no tiene un núcleo de competencias estatutariamente garan- 
tizado: todas son compartidas con otras instituciones (Generalitat, diputación provincial, municipio, mancomunidad y entidad metropolitana). La operatividad de la comarca depende de las funciones que pueda absorber de otros entes preexistentes, a los que tiene que sustraer parte de sus competencias. Mientras los otros entes de la Administración local no desaparezcan, las competencias de la comarca dependen de la capacidad de pacto con dichos entes, en definitiva, del principio de voluntariedad y colaboración entre comarca, municipio y diputación (Fuentes et al., 2001: 79). Esto supone, en la práctica, que, en el ámbito de las competencias, cada comarca tome su propio camino - y así, actualmente, hay consells comarcals con competencias en museos, archivos, ciertos ámbitos de enseñanza y de urbanismo, o en la prestación de algún servicio municipal concreto-- de tal manera que no puede hablarse de un sistema comarcal homogéneo. Por lo que respecta a su precaria financiación, los ingresos de los consells comarcals derivan de transferencias de la Generalitat, que garantizan su supervivencia, y de subvenciones finalistas sobre la vía de diferentes programas (Fuentes, 2014: 62-63). La falta de recursos y competencias, según Burgueño (2001: 198), ha instrumentalizado los consells comarcals y los ha convertido en una herramienta clientelar de la Generalitat. Además, el nuevo Estatuto de 2006, lejos de reforzar el papel de las comarcas, considera que la estructura básica local territorial de Cataluña la determinan el municipio y la veguería, y no el municipio y la comarca, como en el Estatuto de 1979. Burgueño (2014: 103) propone que, para reforzar el papel de las cada vez más devaluadas comarcas, estas deberían convertirse al menos en circunscripciones electorales, en sustitución de los partidos judiciales, para la elección de los diputados provinciales.

En cuanto al desarrollo de la tercera ley de la LOT, el intento de crear las veguerías (figura 7) en sustitución de las provincias, recogido en el Estatuto de 2006, fue paralizado por el Tribunal Constitucional, a instancias del recurso presentado por el Partido Popular contra varios de sus artículos, en la sentencia de 28 de junio de 2010, que imposibilitaba en la práctica la creación de las siete veguerías. Dicha sentencia decía que para que la veguería fuera constitucional debía o bien convertirse en una entidad local distinta de la provincia - $-\mathrm{y}$, por lo tanto, el consell de vegueria sería otro nuevo ente territorial concurrente con la diputación- $\mathrm{o}$ bien sustituir nominalmente a las diputaciones provinciales (que pasarían a llamarse consells de vegueria), sin posibilidad de modificar el límite de las cuatro provincias vigentes (Nel.lo, 2014: 76). En referencia a esta imposibilidad de alterar los límites provinciales vigentes, Argullol (2014: 52) argumenta que existe un debate en la opinión pública española en cuyo marco se llega a afirmar que el Estado de las autonomías es el más descentralizado de Europa. Se obvia, sin embargo, que en gobiernos federales como los Estados Unidos o Alemania, el régimen local depende de las entidades federadas (states, Länder), que no solo transfieren las competencias a los entes intermedios, sino que, además, ajustan los límites de estos de acuerdo con las diversas realidades territoriales de cada entidad federada, para garantizar el encaje más idóneo de aquellas en esta.

Tras la sentencia del TC, el mapa territorial de Cataluña está definido, en estos momentos, por las cuatro provincias intocables, además de por la previsión legal 
—obstaculizada por la sentencia del TC — de siete veguerías (Barcelona, Girona, Central, Alt Pirineu i Aran, Ponent, Camp de Tarragona y Terres de l'Ebre) (figura 7), con sus respectivas delegaciones del Gobierno de la Generalitat, que ya existen actualmente (Barcelona, Girona, Manresa, Tremp, Lleida, Tarragona y Tortosa). Además, este mapa de veguerías coincide con el mapa de las siete áreas funcionales establecidas en 1995 en el Pla Territorial General de Catalunya.

En cuanto al progreso de la cuarta ley - la metropolitana-, la concurrencia de organismos e interlocutores en el área de Barcelona se mantuvo hasta 2010, cuando se creó una nueva entidad: el Área Metropolitana de Barcelona (AMB: 36 municipios, $42 \%$ de la población catalana) ${ }^{12}$, que había de agrupar a las dos entidades metropolitanas creadas en 1987 (la de transporte y la de servicios hidráulicos y tratamiento de residuos) y la mancomunidad de municipios existente. El AMB tendría competencias en territorio y urbanismo, movilidad, vivienda, medio ambiente, desarrollo económico y cohesión social. El primer Consell Metropolità de l'AMB se creó tras las elecciones de mayo de 2011, pero hasta hoy ha ejercido un papel discreto, quizá explicable por la situación económica y por el complejo equilibrio político en sus órganos de gobierno (Nel.lo, 2014: 75). Para simplificar todavía más el ámbito del AMB, el Proyecto de Ley de gobiernos locales que hoy se encuentra en tramitación en el Parlamento de Cataluña pretende eliminar la comarca allí donde el AMB tenga competencias. Fuentes (2014: 64-65) considera que la comarca es una entidad local necesaria, pero que no es imprescindible que haya comarcas en todo el territorio.

En resumen, podemos afirmar que las posibilidades de reforma territorial que se derivaban de la aprobación del Estatuto de 2006 se vieron frustradas, en gran medida, por la sentencia del TC y por la evolución política posterior. A menos que se produzcan cambios institucionales de gran alcance, no parece que vaya a producirse un avance significativo en esta materia a corto plazo.

\section{Conclusiones}

El nuevo modelo de estado autonómico descentralizado que surgió de la Constitución española de 1978 no afectó ni a los municipios ni a las provincias, que continuaron con la misma configuración que había diseñado Javier de Burgos en 1833. El joven régimen democrático aprovechó las estructuras municipales y provinciales ya existentes y les superpuso una nueva forma de organización descentralizada — las comunidades autónomas_-, sin que se reflexionara apenas sobre si la estructura provincial era compatible con la autonómica.

Solo algunas comunidades autónomas han llevado a cabo procesos de creación de entes territoriales administrativos a medio camino entre la provincia y el municipio, con diferentes grados de éxito en su implementación. Los diferentes proyectos de comarcalización de Andalucía, obstaculizados por la fuerte identificación con la provincia y el municipio, por el momento no han sido fructíferos. En Galicia, llegó a ponerse en práctica un proceso de comarcalización

12. Véase <http://ssweb.seap.minhap.es/REL/frontend/inicio/areas_metropolitanas >. 
que fracasó y en estos momentos se está llevando a cabo otra restructuración territorial de manera incipiente, en este caso de carácter asimétrico, mediante la creación de áreas metropolitanas frente a áreas rurales. En Valencia, las comarcas solo funcionan a nivel estadístico, pero tanto en esta comunidad como en la del País Vasco los gobiernos respectivos han promovido una serie de áreas funcionales para la planificación territorial, que superan los límites provinciales y que, en el caso de Euskadi, no coinciden con las cuadrillas o comarcas oficiales alavesas. Solo en el caso mencionado de Álava, el de El Bierzo y los de Aragón y Cataluña, las comarcas gozan de ciertas competencias transferidas. La experiencia aragonesa, todavía sin cerrar (falta por resolver el área metropolitana de Zaragoza) es demasiado reciente como para valorar sus resultados, mientras que la catalana, mucho más dilatada en el tiempo, no ha dado los frutos esperados, a causa de la indefinición de las atribuciones de cada comarca, que, a menudo, chocan con las de las diputaciones y/o los municipios.

Por lo tanto, a la pregunta que nos habíamos planteado sobre si la implantación de comarcas - con competencias transferidas en mayor o menor gradoha contribuido a superar los obstáculos existentes en la organización territorial, podemos decir que, de momento, no demasiado. Quizá haya faltado flexibilidad, al haberse intentado aplicar sistemáticamente un modelo territorial homogéneo - tal vez copiando el modelo uniformizador de las provincias—, cuando en realidad algunos municipios deberían ajustarse a un determinado tipo de ente territorial comarcal, mientras que otros sería más lógico que formasen parte de entidades de tipo metropolitano. La diversidad territorial es un factor primordial a la hora de implementar una nueva administración local, dado que la complejidad del territorio reclama una pluralidad tipológica de entes territoriales — por lo que respecta tanto a su organización como a sus funciones-, a fin de poder dar una respuesta apropiada a cada realidad local. Además, debe buscarse un equilibrio entre consideraciones funcionales e identitarias, que suelen ser complejas y cambiantes, y casi nunca satisfacen a todos. Para dar respuesta, pues, a las realidades territoriales cambiantes, se debería partir de una administración local flexible en cuanto a los tipos de entes, pero también en referencia a su delimitación.

$\mathrm{Si}$, hasta el momento, el papel de los geógrafos — como hemos visto a lo largo de este trabajo - ha sido esencial en el diseño de las propuestas de comarcalización de Andalucía, Aragón, Cataluña, Galicia, Valencia y otros territorios, también a ellos les corresponde formular nuevas propuestas alternativas para la construcción de una organización territorial más eficaz y más adecuada para cada realidad local.

\section{Referencias bibliográficas}

Alberdi, Alberto (2004), «Euskadi Ciudad Global y la Nueva Gobernanza Territorial». Mesa redonda del curso Ciudades Región Globales: El nuevo papel de las autoridades urbanas y regionales en la gestión de las políticas públicas. Donostia-San Sebastián.

Argullol, Enric (2014). «El paper dels governs locals intermedis: Entre la vegueria i la província». Treballs de la Societat Catalana de Geografia, 78, 49-52. 
BARberÁn, Ramón (2003). «La comarcalización de Aragón: Una perspectiva económica». Economía Aragonesa, 21, 50-86.

Benabent, Manuel (coord.) (1998). Estudio territorial para la delimitación de ámbitos comarcales en Andalucía. Sevilla: Arenal Consultores.

Bernadí, Xavier y Galán, Alfredo (2012): El debate actual sobre las diputaciones provinciales: Un análisis de las últimas propuestas electorales. Fundación Democracia y Gobierno Local.

Bielza, Vicente (1992). Bases y propuesta para la comarcalización de Aragón. Zaragoza: Gobierno de Aragón.

BurgueÑo, Jesús (1995). «La génesis de la división territorial contemporánea en la España atlántica (Galicia, Asturias, Cantabria y El Bierzo)». Ería, 36, 5-33.

- (2001). «Geografía y administración: Proyectar territorios en el siglo XxI». Boletín de la Asociación de Geógrafos Españoles, 32, 191-207.

- (2003). Història de la Divisió Comarcal. Barcelona: Rafael Dalmau Editor.

- (2014). "Conclusions i cloenda de la jornada sobre l'organització territorial dels governs locals». Treballs de la Societat Catalana de Geografia, 78, 99-106.

Burgueño, Jesús y Guerrero, Montse (2014). «El mapa municipal de España: Una caracterización geográfica». Boletín de la Asociación de Geógrafos Españoles, 64, 11-36.

Burgueño, Jesús y Lasso, Ferran (2002). Història del mapa municipal de Catalunya. Barcelona: Direcció General d'Administració Local.

Burriel, Eugenio (2009). «La planificación territorial en la Comunidad Valenciana (1986-2009)». Scripta Nova: Revista Electrónica de Geografía y Ciencias Sociales, XIII, 306.

Cano, Gabriel (1984). «Comarcalización y Reforma Agraria en Andalucía». Revista de Estudios Andaluces, 3, 101-124.

- (1989). «Divisiones territoriales y comarcalizaciones en Andalucía. Pasado y presente». Geografía de Andalucía, tomo vir. Sevilla: Tartessos, 23-90.

- (2002). «Una propuesta de comarcalización para Andalucía». Conocer Andalucía: Gran Enciclopedia Andaluza del Siglo XXI, volumen 10. Sevilla: Tartessos, 11-85.

Compán, Diego (1983). «Aportaciones al proyecto de comarcalización de la Junta de Andalucía». Cuadernos Geográficos, 13, 183-202.

Copano, Luis y Ventura, Jesús (2013). "Ámbitos intermedios en la provincia de Cádiz dentro de los procesos comarcalizadores en Andalucía». Cuadernos Geográficos, 52, 318-348.

DÁvila, Nagore (2012): «Las características naturales como factor inicial para una correcta planificación territorial: Una aplicación al área funcional de DonostialdeaBajo Bidasoa (País Vasco)». Boletín de la Asociación de Geógrafos Españoles, 60, $187-202$.

FERret, Joaquim (2014). «El mapa municipal en qüestió i l'ajornament de la seva reforma». Treballs de la Societat Catalana de Geografia, 78, 35-40.

Fuentes, Josep R. (2014). «Un nou paper per a les comarques : Qüestionar-les, reforçar-les, reduir-les, ampliar-les?». Treballs de la Societat Catalana de Geografia, 78, 61-68.

Fuentes, Josep R.; Gifreu, Judith; Renyer, Jaume y Sabaté, Josep M. (2001). Introducció al dret local $i$ urbanistic de Catalunya. In memoriam de Màrius Viadel i Martín. Valencia: Tirant lo Blanch.

Gil Olcina, Antonio (1999). «Fuero y jurisdicción alfonsinos en la génesis de los municipios valencianos». Estudios Geográficos, 237, 613-650. 
INFANTE, Jorge (2010). «Aproximación al modelo de comarcalización de Aragón: Una reflexión crítica». Boletín de la Asociación de Geógrafos Españoles, 52, 59-80.

Lluch, Enric y Nel-Lo, Oriol (1983). La gènesi de la divisió territorial de Catalunya (1931-1936): Edició de documents de l'arxiu de la ponència. Barcelona: Diputació de Barcelona.

- (1984). El debat de la divisió territorial de Catalunya (1939-1983): Edició d'estudis, propostes i documents. Barcelona: Diputació de Barcelona.

LoIs, Rubén y Aldrey, José (2010). «El problemático recorrido de la ordenación del territorio en Galicia». Cuadernos Geográficos, 47, 583-610.

Membrado, Joan C. (2013). «La división territorial valenciana: Antecedentes, problemas y política de la Generalitat». Investigaciones Geográficas, 59, 5-24.

MendizÀbal, Enric (2014). «El mapa municipal en qüestió i l'ajornament de la seva reforma». Treballs de la Societat Catalana de Geografia, 78, 21-34.

Ministerio de Hacienda y Administraciones Públicas (sin fecha). Registro de Entidades Locales del Estado [en línea]. <http://ssweb.seap.minhap.es/REL/frontend/inicio/index>.

Muñoz, Arancha y Doménech, Vicent (2012). Comunitat Valenciana 2030: Síntesis de la Estrategia Territorial. Generalitat Valenciana.

NADAL, Francesc (1987). Burgueses, burócratas y territorio: La politica territorial en la España del siglo XIX. Madrid: Instituto de Estudios de Administración Local.

NeL·LO, Oriol (2014). «Realitats metropolitanes i governs locals». Treballs de la Societat Catalana de Geografia, 78, 69-94.

Orduña, Enrique (2003). «Nuevas aportaciones sobre el mapa municipal español». Revista de Estudios de Administración Local, 291, 779-826.

PAüL, Valerià y PAzos, Miguel (2009). «Els darrers capítols del debat al voltant del mapa immutable de Galícia: Qüestions actuals d'organització territorial gallega». Treballs de la Societat Catalana de Geografia, 67-68 y 199-229.

Pezzi, Manuel (1982). La comarcalización de Andalucía. Publicaciones de la Universidad de Granada.

Piqueras, Juan y Membrado, Joan C. (1995). «La política territorial de la Generalitat Valenciana: La comarcalització pendent». Cuadernos de Geografia, 58, 337-364.

Precedo, Andrés (1974). "Galicia: Red urbana y desarrollo regional». Boletín de la Real Sociedad Geográfica, CX, 1-12.

- (1987). Galicia: Estructura del territorio y organización comarcal. Santiago: Xunta de Galicia.

- (2004). «El modelo de desarrollo comarcal». Boletín de la Asociación de Geógrafos Españoles, 38, 29-47.

QuintanA, Tomás (1993). «Las comarcas en Castilla y León: La comarca de El Bierzo». Revista Aragonesa de Administración Pública, 3, 11-25.

Rodríguez, Román (2006). «El territorio local en Europa: Reestructuración de su base organizativa y posibilidades para España». Xeográfica: Revista de Xeografía, Territorio e Medio Ambiente, 6, 115-132.

Souto, Xosé M. (1983). «O problema da rexionalización en Galicia: Encol da rexión urbana de Vigo". Sociedade Galega de Xeografía, 1, 153-183.

Torres, Francesc (1998). "Geografia política i municipi: Els termes generals com a forma d'organització del territori valencià». Cuadernos de Geografía, 63, 245-265.

Zoido, Florencio (coord.) (2001). Informe de desarrollo territorial de Andalucía. Grupo de investigación Estructuras y Sistemas Territoriales. 